\title{
GREEN SUPER RICE GENOTYPES EXHIBITED SUPERIOR MORPHOLOGICAL TRAITS AND HIGHER YIELD ADVANTAGE OVER CHECK UNDER RAINFED LOWLAND CONDITION
}

\author{
Dhakal Krishna*, Ghimire Surya Kant, Kharel Raju \\ Department of Genetics and Plant Breeding, Agriculture and Forestry University, \\ Chitwan, Nepal \\ Yadaw Ram Baran \\ Nepal Agricultural Research Council, National Rice Research Program, Hardinath, \\ Dhanusa, Nepal \\ Pokhrel Keshab Raj \\ Nepal Agricultural Research Council, Agriculture Research Station, Dasharathpur, \\ Surkhet, Nepal \\ Prem Bahadur Magar \\ Nepal Agricultural Research Council, Plant Pathology Division, Khumaltar, Lalitpur, Nepal \\ *E-mail: krishnadhakal19@gmail.com \\ ORCID: 0000-0001-9601-6493
}

\begin{abstract}
Drought, mostly, is major limitation of rainfed lowland rice. Varieties that can escape or tolerate moisture stress are desirable for increasing production and contributing food security of the country as rice is most consumed among the cereals and contribute largely in total cereal production. With objective of identifying early maturing and high yielding rice genotypes having potentiality to escape or tolerate moisture stress, a total of twenty rice genotypes tested in a Randomized Complete Block design. Statistical analysis revealed that genotypes were highly significant for most of the traits under observation. Green super rice genotype HHZ10-DT7-Y1 was found superior in performance for most of the measured morphological traits viz. highest grain yield, thousand grain weight and biomass yield, but found statistically at par with Hardinath- 3 (check) in maturity. Similarly, HHZ1-DT3-Y1-Y1 recorded highest harvest index, number of filled grains/ panicle, earliest days to flowering and maturity. Yield advantage of HHZ lines, except HHZ25-DT9-Y1-Y1, over check was 19 to almost $45 \%$, and 28.51 to 56 . $22 \%$ more than national average grain yield in rainfed condition. Water table was lower, and recorded none after $6^{\text {th }}$ week of measurement. Plant height, panicle length, thousand grain weight, harvest index, days to flowering, days to maturity were identified as important traits for future grain yield improvement program based on their heritability study.
\end{abstract}

\section{KEY WORDS}

Green super rice, grain yield, heritability, rainfed rice, water table.

Food security of the country is largely dependent on rice as it is most preferred among cereals and covers large share of area and production in total grain production. In mountains, percentage of rainfed rice area almost equals irrigated rice followed by $40 \%$ in hills, $25 \%$ in terai, and overall 30\% area coverage in the country (MoALD, 2017). Globally, it holds considerable contribution of about $19 \%$ of the world's rice production from about 52 million hectares of land (GRiSP, 2013). Occurrence of drought has been a major issue limiting rice cultivation and production, creating huge yield gap and challenging food security of the country. In a study, conducted in two different places of Thailand, the actual yield loss in rice due to drought was $59-68 \%$ in Nakhonratsima and $55-65 \%$ in Kalasin, respectively compared 
with the attainable yield (Polthanee and Promkhambut, 2014). Similarly, under drought stress, yield reduction reported were 27.31 to $67.7 \%$ (Kumar et al., 2015), and 12 to $46 \%$ (Ouk et al., 2006) respectively. With the reduction in yield, area under rice cultivation has also been decreasing. Gumma et al. (2011) observed a significant decline (13\%) in rice cultivated area in 2006 and also found that the higher reduction in rice area was mainly restricted to the rainfed districts of the eastern, central, and mid-western regions of Nepal due to severe drought incidence. Rice varieties under cultivation in rainfed lowlands were lower yielding (national average- $2.49 \mathrm{t} / \mathrm{ha}$ ); almost $34 \%$ less yield to irrigated field (MoALD, 2017) and needed to be increased to meet increasing demand. Due to less alternatives of high yielding stress tolerant varieties, farmers could not able to get expected yield from rainfed rice, making farmers more vulnerable to food scarcity. According to Tripathi et al. (2018) the major focus in rice breeding for Nepal is to develop high yielding and stress tolerant rice genotypes with desirable grain qualities.

This research, thus, was carried out with the objectives of screening early maturing and high yielding rice genotypes and identifying important traits for grain yield improvement under rainfed lowland condition. The main highlight of this study was green super rice genotypes. These genotypes were developed by Chinese academy of agricultural sciences in collaboration with International Rice Research Institute by blending several varieties that can perform better even in poor soil and stress environments. Developed genotypes were tested in different countries of Asia and Africa, and several varieties are being released (IRRI, 2016, and Li and Ali, 2017).

\section{MATERIALS AND METHODS OF RESEARCH}

Field experiment. Twenty genotypes of early rice genotypes were provided from National Rice Research Program (NRRP). Those genetic materials were B11586-FMR-11-R2-11, IR 55423-01, IR 88965-39-16-4, IR 08L-181, IR 10L 182, IR 09L 342, HHZ12-SAL2Y3-Y2, HHZ10-DT7-Y1, IR 11N 400, IR 09N 542, HHZ1-DT3-Y1-Y1, HHZ25-DT9-Y1-Y1, HHZ14-DT12-LI1-LI1, IR 14L 116, IR 97096-15-1-1-3, IR 95814-10-2-2-2, IR 14D 196, IR 14D 198, IR 14D 199, Hardinath-3 respectively which included five lines of super green rice genotypes (HHZ lines), and (Hardinath-3) drought tolerant variety as check genotype.

Seed bed preparation and sowing was done on June 22, 2017. Experiment was conducted in breeding block of Agriculture Research Station, Dasharathpur, Surkhet $\left(28^{\circ} 30^{\prime}\right.$ northern latitude, $81^{\circ} 47^{\prime}$ eastern longitude, and 490 meter above mean sea level) from June to November, 2017 using Randomized Complete Block Design. Soil of research site was neutral with $\mathrm{pH}$ value of $6.8,3.89 \%$ soil organic matter, $0.19 \%$ Nitrogen, $209.31 \mathrm{~kg} / \mathrm{ha}$ Phosphorous, $131.9 \mathrm{~kg} / \mathrm{ha}$ Potassium and sandy loam soil texture. Within the field, replications were spaced 1 meter apart whereas plots within the replications were spaced 50 $\mathrm{cm}$. Individual plot size was $10 \mathrm{~m}^{2}(5 \mathrm{~m} \times 2 \mathrm{~m})$ with 10 rows and 25 hills which were $20 \mathrm{~cm} \times$ $20 \mathrm{~cm}$ apart. 25 days old seedlings, 3 seedlings/ hill, were transplanted on July 17, 2017. Harvesting in each plot was done by excluding two lines, so net plot during harvesting was $5.04 \mathrm{~m}^{2}(4.2 \mathrm{~m} \times 1.2 \mathrm{~m})$. Two supplementary irrigations were provided at 55 and 64 days after transplanting. All other cultural practices were performed as when it was required by following recommended practices. Agro- meteorological data of research site during the study period is presented in Table 1.

Water table. For studying water table of the field, three perforated PVC pipes were installed, one in each of three replications. All three pipes were one meter in length and $30 \mathrm{~mm}$ in diameter. $80 \mathrm{~cm}$ length of the perforated pipe was inserted below the ground level and $20 \mathrm{~cm}$ length remained above ground level. While inserting the pipes, lower portion of pipes were covered with cloth so as to prevent entry of soil inside the pipes. Pipes were made porous by making holes of less than $2 \mathrm{~mm}$ diameter all around the pipe. Daily observations were taken at morning time with the help of aluminum tape beginning from 30 days after transplantation. The method was slightly modified from Saleh and Bhuiyan (1995). Water table from three replications were recorded in centimeter in a daily basis starting from 30 days after transplantation and later expressed as average weekly water table. 
Table 1 - Agro- meteorological data of research site from June to October, 2017

\begin{tabular}{llllll}
\hline \multirow{2}{*}{ Month } & \multicolumn{2}{l}{ Average Temperature } & Average Humidity $(\%)$ & Rainfall $(\mathrm{mm})$ \\
\cline { 2 - 6 } & Maximum $\left({ }^{\circ} \mathrm{C}\right)$ & Minimum $\left({ }^{\circ} \mathrm{C}\right)$ & $8: 45$ AM & $5: 45 \mathrm{PM}$ & Total \\
\hline June & 35.1 & 22.3 & 74.01 & 69.2 & 189 \\
July & 33.2 & 22.4 & 88.35 & 84.8 & 421.5 \\
August & 32.9 & 22.1 & 89.42 & 86.4 & 720 \\
September & 34 & 22.6 & 85.65 & 83.3 & 0 \\
October & 32.1 & 18.7 & 83.87 & 76.09 & 0 \\
\hline
\end{tabular}

Source: Department of Hydrology and Meteorology, Mid \& Far Western Regional Climate Office, Surkhet, Nepal.
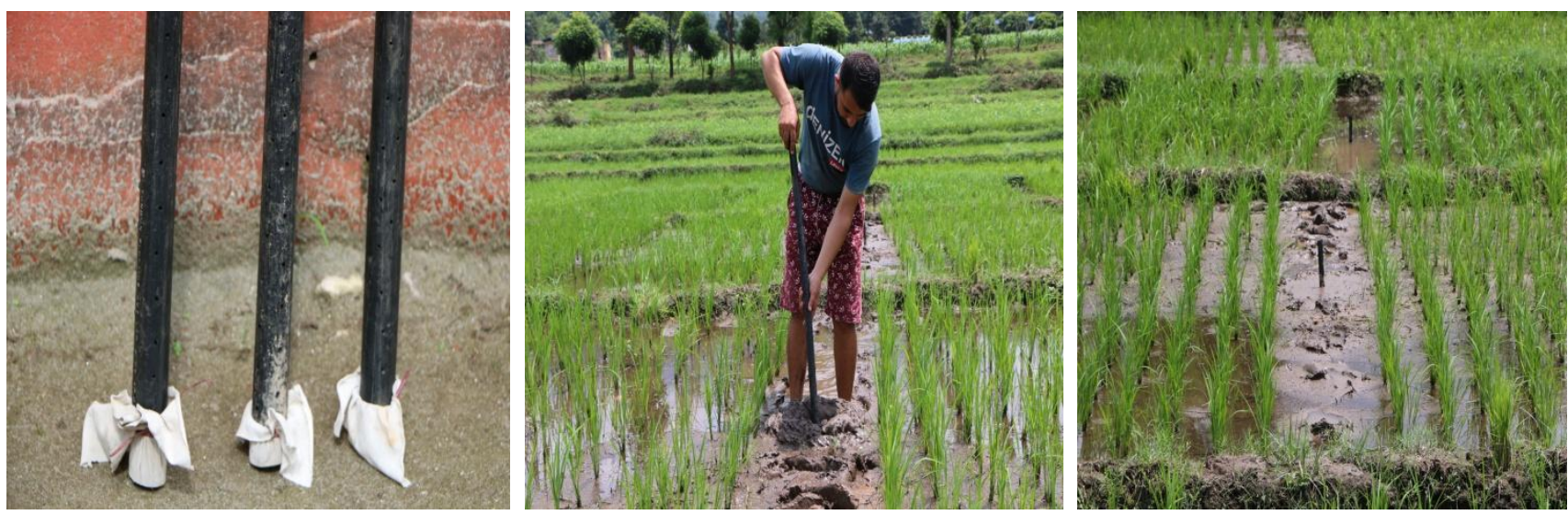

Figure 1 - a) Perforated PVC pipes with lower end closed with cloth, b) Installing pipes in the field,

c) Installation of pipes in all three replications

Data recording. Data were recorded from ten randomly selected plants per plot (excluding border plants) separately for plant height $(\mathrm{cm})$, panicle length $(\mathrm{cm})$, flag leaf area $\left(\mathrm{cm}^{2}\right)$, number of effective tillers/ $\mathrm{m}^{2}$, thousand grain weight $(\mathrm{g})$, biomass yield $(\mathrm{kg} / \mathrm{plot}$ ), harvest index, number of filled and unfilled grains/ panicle. Days to flowering and days to maturity were recorded based on the $50 \%$ and $85 \%$ population observation respectively. Straw, biomass and grain yield (kg/ plot) were converted to tons/ hectare ( $\mathrm{t} / \mathrm{ha}$ ) for the analysis. While recording data, standard protocol of International Rice Research Institute was followed (IRRI, 2013).

Data analysis. Data entry and processing were done using Microsoft Office Excel 2007 and 2010. Heritability in broad sense was estimated as suggested by Johnson et al. (1955). Analysis of variance and calculation of means were done using R-Program 3.5.2 and Crop Stat 7.2 software.

\section{RESULTS AND DISCUSSION}

Water table. The experimental site had lower water table throughout the study period. Water table in the field during first week of recording (37 days after transplanting) was 23.09 $\mathrm{cm}$ followed by $22.86 \mathrm{~cm}, 0 \mathrm{~cm}, 11.76 \mathrm{~cm}, 11.5 \mathrm{~cm}$ and $1.24 \mathrm{~cm}$ respectively in $2^{\text {nd }}, 3^{\text {rd }}, 4^{\text {th }}$, $5^{\text {th }}$ and $6^{\text {th }}$ weeks of measurement. Moreover, water table was none after sixth week of measurement; 72 days after transplantation. Low water table in the field was favored by sandy loam characteristics of soil. When the amount of clay in the soil decreases, or soil texture become coarser, downward movement of water increases and water holding capacity of soil decreases, ultimately, water table and moisture in the soil decreases. After the end of August, water table in the field decreased to even lower level (Figure 2) that was because of higher temperature and no rainfall (Table 1). Similar findings on soil texture and soil moisture were put forward by Tsubo et al. (2007) and Dou et al. (2016). 


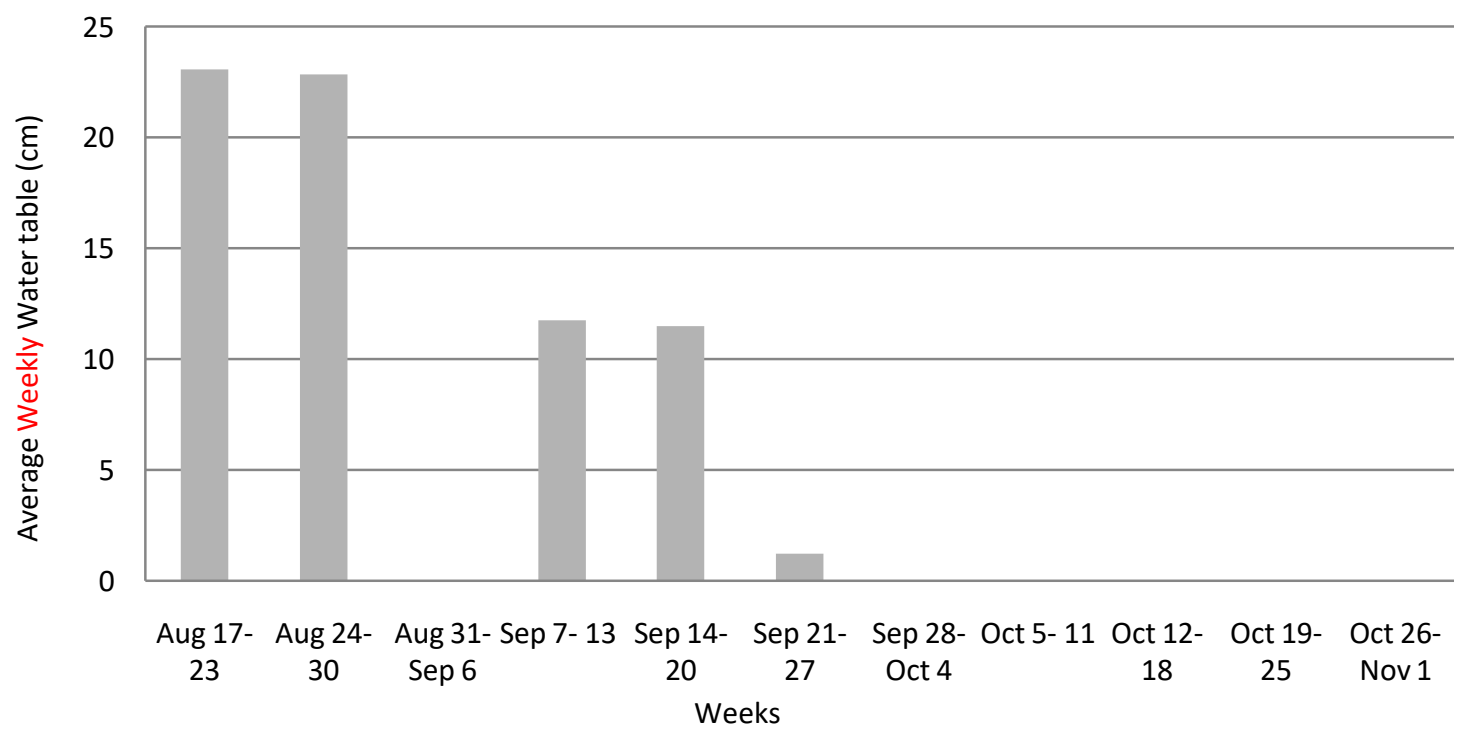

Figure 2 - Average weekly water table of the experimental field measured after 30 days of transplantation

Morphological Traits. Genotypes, under study, were highly significant for the traits viz. plant height, panicle length, flag leaf area, number of effective tillers/ $\mathrm{m}^{2}$, grain yield, thousand grain weight, grain yield, straw yield, harvest index, number of filled grains/ panicle, days to flowering and maturity, and were significantly different for biomass yield. The detail performance of twenty genotypes for each observed traits under rainfed lowland condition are presented in Table 2 and 3.

Plant Height: Among twenty, seven genotypes had plant height below $100 \mathrm{~cm}$. The shortest plant height was recorded in HHZ1-DT3-Y1-Y1 $(85.13 \mathrm{~cm})$ followed by HHZ14DT12-LI1-LI1 $(89.57 \mathrm{~cm})$, HHZ25-DT9-Y1-Y1 $(89.71 \mathrm{~cm})$, IR 10L $182(91.47 \mathrm{~cm})$ whereas, Hardinath- 3 recorded tallest plant height $(117.29 \mathrm{~cm})$. Genotypes with shorter plant stature (dwarf genotypes) in this experiment yielded more in comparison to those with taller plant stature (Table 2). This might be due to more water requirement of taller plants to maintain their overall biomass, hence experienced more water stress during the growth period. In line with this result, enhanced drought tolerance ability of dwarf rice genotypes and higher yielding ability was reported by Ahmadikhah and Marufinia (2016). Similarly, Fukai et al. (1999) stated that genotypes having drought tolerance ability also have intermediate plant stature under rainfed lowland condition. Allah et al. (2010) also reported that plant height had negative and low direct effect to grain yield under drought stress, which agrees with findings of this research. Selected superior double haploid lines based on grain yield and agronomic characters by Akbar et al. (2019) also had plant height range of $85.7-124.7 \mathrm{~cm}$ in rainfed lowland rice.

Number of Effective Tillers/ $\mathrm{m}^{2}$ : Compared to the check, more than $50 \%$ genotypes had higher number of effective tillers per $\mathrm{m}^{2}$. IR 14D 199 (280), IR 14L 116 (275) and IR 95814-10-2-2-2 (274) respectively had highest number of effective tillers whereas IR 5542301 (188), IR 08L-181 (195) and HHZ1-DT3-Y1-Y1 (200) had lowest number of effective tiller/ $\mathrm{m}^{2}$. Green super rice genotypes had 8- 10 tillers per plant and produced higher grain yield in the experiment (Table 2). According to Li and Ali (2017) GSR were developed to tolerate drought stress and low input condition, and possesses medium tillering ability. Genotypes with higher number of tillers might have suffered from moisture stress due to low moisture extraction from the soil specially during their reproductive stage. As a result, they produced grains with less dry matter deposition in it, which decreased grain yield in comparison to early maturing genotypes with lower to medium tillers. Akbar et al. (2019) in accord with current finding reported that genotypes with 8.6-14.8 tillers per plant in rainfed lowland rice had high yield as well as superior agronomic characters. The author also reported that 
productive tillers had a positive correlation and direct effect on productivity. In contrast to it, lower positive correlation and negative low direct effect of tillers per plant to grain yield under drought was reported by Allah et al. (2010).

Panicle Length, Filled Grains/ Panicle, and Thousand Grain Weight: Panicle length of 16 genotypes out of 20 were between $23-27 \mathrm{~cm}$. Longest panicle length $(28.81 \mathrm{~cm})$ was recorded by IR $11 \mathrm{~N} 400$ followed by IR 14D $196(26.76 \mathrm{~cm})$ and IR $14 \mathrm{~L} 116(26.14 \mathrm{~cm})$ respectively and shortest panicle length by HHZ1-DT3-Y1-Y1 $(22.13 \mathrm{~cm})$ followed by HHZ12SAL2-Y3-Y2 $(22.25 \mathrm{~cm})$ and HHZ25-DT9-Y1-Y1 $(22.73 \mathrm{~cm})$ (Table 2). Highest number of filled grains/ panicle was recovered from HHZ1-DT3-Y1-Y1 (213) followed by HHZ25-DT9Y1-Y1 (204). HHZ10-DT7-Y1 (26.56 g), IR 14L 116 (25.72 g), IR 09L 342 (25.56 g) and HHZ12-SAL2-Y3-Y2 (24.83 g) respectively produced highest thousand grain weight. The value varied from 20.68 grams to 26.56 grams among the studied genotypes (Table 3 ). Panicle length along with filled grains and boldness of grain together determines grain yield of the genotypes. Most of the early flowering genotypes in the experiment, despite having comparatively lower panicle length, recorded higher number of filled grains/ panicle as well as thousand grain weight. This might have been due to partitioning of dry matter at higher rate than other genotypes during grain filling duration. Dry matter partitioning in these early flowered genotypes was favoured by early rainfall and supplementary irrigations provided during 55 and 64 days of transplanting. Kumar et al. (2006b) suggested that genotypes that can partition more dry matter to grain during terminal drought are advantageous to overcome late season moisture stress in rainfed lowland condition. In accord to the present finding, selected superior genotypes under rainfed lowland condition by Akbar et al. (2019) had number of filled grains/ panicle in the range of 137- 265 grains, and thousand grain weight 21.5- $31.3 \mathrm{~g}$. These reports sufficiently supports present finding.

Flag Leaf Area: IR 55423-01 (53.34 $\left.\mathrm{cm}^{2}\right)$ followed by IR 14D $196\left(52.89 \mathrm{~cm}^{2}\right)$ and HHZ10-DT7-Y1 $\left(51.85 \mathrm{~cm}^{2}\right)$ respectively had largest flag leaf area where B11586-FMR-11R-2-11 $\left(36.73 \mathrm{~cm}^{2}\right)$ followed by IR 09N $542\left(37.09 \mathrm{~cm}^{2}\right)$ and IR 14D $198\left(37.39 \mathrm{~cm}^{2}\right)$ had smallest flag leaf area (Table 2). Being advanced breeding lines, genotypes under study were the sets that had been selected and screened for best agronomic traits. Majority of genotypes had broad leaves but only the selected genotypes could record overall superior performance. The difference in performance of these genotypes might be due to their varied level of response to moisture stress occurred during their growth period. Among the broad leaved genotypes, higher yielders again, were green super rice genotypes. Li and Ali (2017) mentioned that green super rice genotypes have longer, broader, thicker and erect types of leaf characteristics which were also observed in this study. Similar to the current finding, Farooq et al. (2010) mentioned that genotypes with broader leaves performed superior over narrow leaved genotypes under drought stress.

Days to 50\% flowering and 85\% Maturity: Flowering and maturity duration are important phenomena for avoiding drought stress in rainfed environments. In the present study, HHZ1-DT3-Y1-Y1 was earliest among the genotypes for flowering (83 days) and maturity (115 days). Nine genotypes flowered earlier than the check genotypes. IR 09N 542 (125 days), IR 14D 198 (125 days), IR 14D 199 (125 days), and IR 55423-01 (125 days), and IR $11 \mathrm{~N} 400$ (125 days) respectively took longest days for maturing and were at par to the check genotype (Table 2). Area where occurrence of terminal drought is very likely, early flowering and maturing genotypes are much favoured as they can escape terminal drought and complete their lifecycle before drought stress (Fukai, 1999). Terminal drought was prominent in the research location as there was no rainfall recorded after August and water table in the field was lower with increased temperature during September (Figure 2) and (Table 1). Highest grain yield in this experiment was recorded from early flowering and maturing genotypes, as they best utilized the early season rainfall and two supplementary irrigations at 55 and 64 days after transplantation. Genotypes that flowered earlier and matured within 120 days of sowing were among the highest yielders; however not all the early maturing genotypes could do so. Genotypes that can partition dry matter directly to the grains during moisture stress condition can only be superior in terms of yield and attributing traits (Kumar et al., 2006a). Monkham et al. (2015) and (Pantuwan et al., 2002) reported 
lower yield reduction in early maturing genotypes under rainfed lowland condition which is in accord with the findings of this research.

Biomass yield and Harvest Index: Biomass yield was recorded highest for HHZ10-DT7Y1 (7.13 t/ha) followed by HHZ12-SAL2-Y3-Y2 (7.11 t/ha) and IR 14D 199 (7.00 t/ha). HHZ1DT3-Y1-Y1 (5.67 t/ha) followed by IR 10L 182 (5.67 t/ha) and B11586-FMR-11-R-2-11 (5.83 $\mathrm{t} / \mathrm{ha}$ ) produced lowest biomass yield. 11 genotypes produced biomass at par with the check genotype. Harvest index was higher for HHZ1-DT3-Y1-Y1 (0.57) followed by HHZ10-DT7-Y1 (0.54) and IR 10L $182(0.54)$ respectively (Table 3 ). Biomass production and harvest index value in the experiment was quite associated with flowering behaviour of the genotypes. Early flowering genotypes recorded higher biomass and harvest index values as these genotypes experienced less water stress because of early flowering behaviour, and utilization of rainfall during early season (Pantuwan et al., 2004). Under drought stress condition, Kumar et al. (2015) reported that genotypes with higher total biomass also produced higher yield advantage. Also, high direct effect of thousand grain weight in yield was reported by Allah et al. (2010).

Table 2 - Means of plant height, panicle length, flag leaf area, number of effective tillers $/ \mathrm{m}^{2}$, and days to flowering and maturity of twenty rice genotypes under rainfed lowland condition

\begin{tabular}{lllllll}
\hline ENTRY & HT & PL & FLA & ET & DTF & DTM \\
\hline B11586-FMR-11-R-2-11 & 104.32 & 23.99 & 36.73 & 210.67 & 85.00 & 117.00 \\
IR 55423-01 & 105.00 & 23.18 & 53.34 & 188.00 & 95.67 & 125.00 \\
IR 88965-39-16-4 & 105.30 & 25.19 & 39.84 & 228.00 & 89.67 & 121.00 \\
IR 08L-181 & 105.93 & 23.66 & 50.11 & 195.00 & 89.00 & 120.00 \\
IR 10L 182 & 91.47 & 24.77 & 48.51 & 201.33 & 85.00 & 119.33 \\
IR 09L 342 & 107.54 & 23.52 & 38.68 & 209.33 & 85.67 & 117.00 \\
HHZ12-SAL2-Y3-Y2 & 100.68 & 22.26 & 48.64 & 244.00 & 87.33 & 119.00 \\
HHZ10-DT7-Y1 & 95.73 & 25.43 & 51.85 & 244.67 & 86.00 & 119.00 \\
IR 11N 400 & 105.93 & 28.81 & 48.60 & 258.67 & 94.33 & 124.67 \\
IR 09N 542 & 99.10 & 25.81 & 37.09 & 247.33 & 95.67 & 125.00 \\
HHZ1-DT3-Y1-Y1 & 85.13 & 22.13 & 38.27 & 199.67 & 83.33 & 115.33 \\
HHZ25-DT9-Y1-Y1 & 89.71 & 22.73 & 48.46 & 248.00 & 86.00 & 117.67 \\
HHZ14-DT12-LI1-LI1 & 89.57 & 23.65 & 45.29 & 225.67 & 87.00 & 120.00 \\
IR 14L 116 & 104.50 & 26.15 & 42.58 & 274.67 & 85.00 & 116.33 \\
IR 97096-15-1-1-3 & 107.97 & 25.53 & 50.11 & 235.00 & 90.67 & 121.33 \\
IR 95814-10-2-2-2 & 93.16 & 24.69 & 42.43 & 274.33 & 90.67 & 122.00 \\
IR 14D 196 & 109.27 & 26.76 & 52.89 & 240.33 & 93.67 & 123.00 \\
IR 14D 198 & 102.15 & 25.31 & 37.40 & 266.33 & 97.00 & 125.00 \\
IR 14D 199 & 102.65 & 25.61 & 39.12 & 279.67 & 96.33 & 125.00 \\
Hardinath-3 (Check) & 117.29 & 24.76 & 49.50 & 231.00 & 89.33 & 119.67 \\
Grand Mean & 101.12 & 24.70 & 44.97 & 235.08 & 89.62 & 120.62 \\
F- test & $* *$ & $* *$ & $* *$ & $* *$ & $* *$ & $* *$ \\
SEM & 2.74 & 0.72 & 3.41 & 14.84 & 0.53 & 0.50 \\
LSD (5\%) & 7.84 & 2.05 & 9.77 & 42.48 & 1.53 & 1.44 \\
CV (\%) & 4.70 & 5.00 & 13.10 & 10.90 & 1.00 & 0.70 \\
Heritability (\%) & 88.64 & 81.05 & 65.9 & 71.69 & 98.54 & 97.47 \\
\hline
\end{tabular}

Coefficient of Variation (CV), Standard Error of Mean (SEM), Least Significant Difference (LSD), HT- Plant height (cm), PL- Panicle length (cm), FLA- Flag leaf area $\left(\mathrm{cm}^{2}\right)$, ET- Number of effective tillers/ $\mathrm{m}^{2}$, DTF- Days to flowering, DTM- Days to maturity, F- test ( ${ }^{*}$-significant at $5 \%$ level of significance, ${ }^{* *}$-significant at $1 \%$ level of significance).

Grain Yield and Yield Advantage Over Check: Highest grain yield was recorded by HHZ10-DT7-Y1 (3.89 t/ha) followed by HHZ12-SAL2-Y3-Y2 (3.37 t/ha), HHZ1-DT3-Y1-Y1 (3.28 t/ha) and HHZ14-DT12-LI1-LI1 (3.20 t/ha) respectively. IR 14D 198 (2.5 t/ha), IR 14D 196 (2.55 t/ha), IR 55423-01 (2.57 t/ha) and Hardinath-3 (2.69 t/ha) were among the lowest yielders. Yield of the genotypes under study condition varied from 2.50 t/ha to $3.89 \mathrm{t} / \mathrm{ha}$. Highest grain yielder genotype HHZ10-DT7-Y1 (3.89 t/ha) yielded $44.60 \%$ more grain to the check genotype. Top grain yielders in the study were super green rice genotypes. Yield advantage of HHZ lines, except HHZ25-DT9-Y1-Y1, over check was 19 to almost $45 \%$, and 28.51 to $56.22 \%$ more than national average grain yield in rainfed condition (Figure 3 ). The superior performance of $\mathrm{HHZ}$ lines even in moisture stress and higher temperature during 
early flowering to maturity duration (Figure 2) (Table 1) was due to their genetic ability to perform extraordinarily in poor environment condition because these genotypes were developed for such conditions (IRRI, 2016). As in this study, range of yield advantage of green super rice genotypes reported were $31-36 \%$ in fully irrigated to drought stressed environments in Philippines (Marcaida et al., 2014).

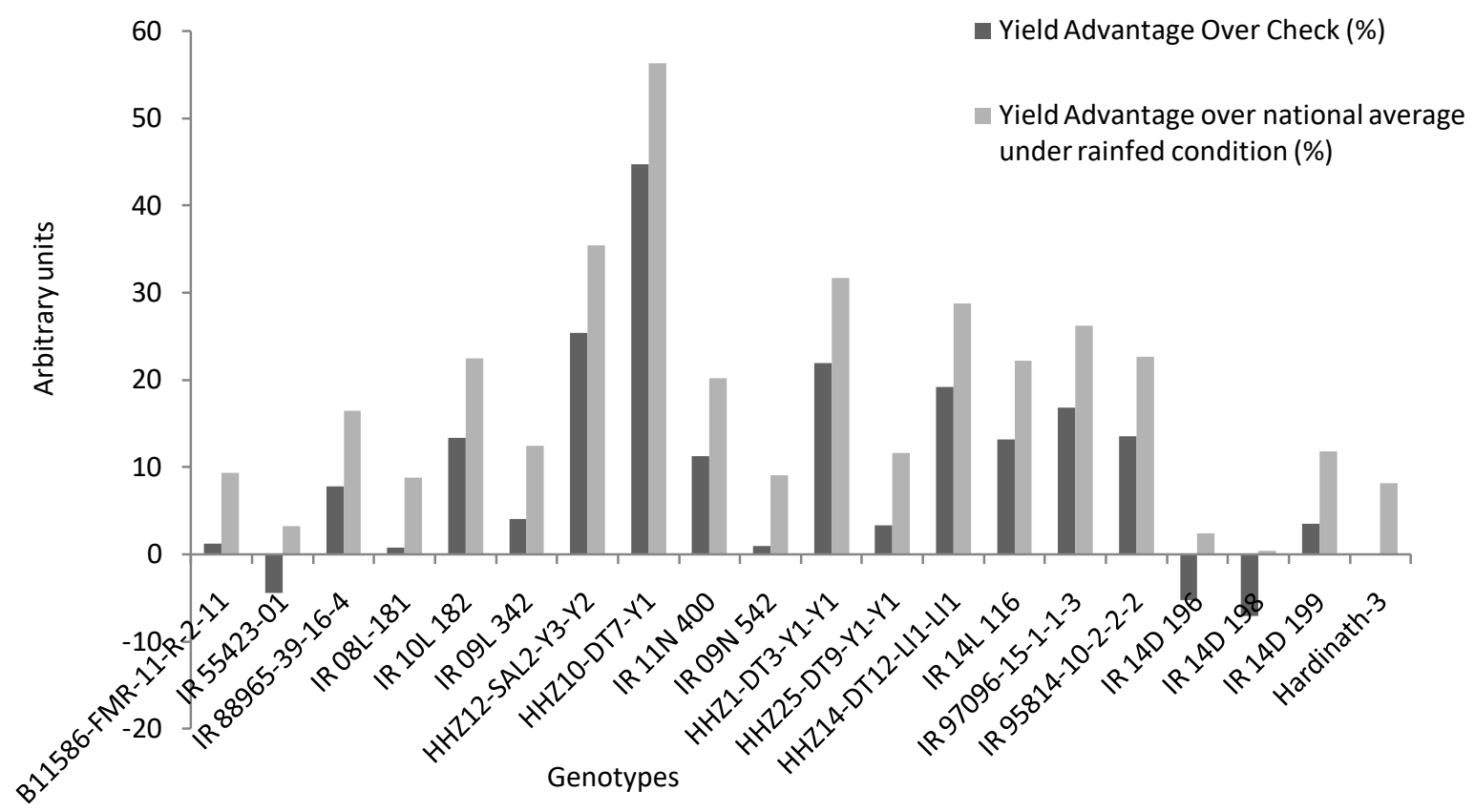

Figure 3 - Bar graph showing percentage yield advantage of genotypes over check (Hardinath-3) and national average grain yield under rainfed condition

Table 3 - Means of straw yield, biomass yield, harvest index, number of filled grains/ panicle, thousand grain weight and grain yield of twenty rice genotypes under rainfed lowland condition

\begin{tabular}{lllllll}
\hline ENTRY & SW & BMS & HI & FGPP & TGW & GY \\
\hline B11586-FMR-11-R-2-11 & 2.99 & 5.83 & 0.48 & 143.73 & 24.27 & 2.72 \\
IR 55423-01 & 3.32 & 5.89 & 0.43 & 165.93 & 21.78 & 2.57 \\
IR 88965-39-16-4 & 3.34 & 6.24 & 0.47 & 153.80 & 24.67 & 2.90 \\
IR 08L-181 & 2.98 & 5.90 & 0.48 & 170.73 & 21.74 & 2.71 \\
IR 10L 182 & 2.63 & 5.68 & 0.54 & 180.97 & 20.68 & 3.05 \\
IR 09L 342 & 3.41 & 6.21 & 0.45 & 147.69 & 25.56 & 2.80 \\
HHZ12-SAL2-Y3-Y2 & 3.74 & 7.11 & 0.47 & 171.83 & 24.83 & 3.37 \\
HHZ10-DT7-Y1 & 3.24 & 7.13 & 0.55 & 174.27 & 26.56 & 3.89 \\
IR 11N 400 & 3.55 & 6.14 & 0.46 & 130.42 & 24.27 & 2.99 \\
IR 09N 542 & 3.59 & 6.05 & 0.43 & 139.80 & 23.12 & 2.72 \\
HHZ1-DT3-Y1-Y1 & 2.39 & 5.67 & 0.58 & 212.93 & 22.96 & 3.28 \\
HHZ25-DT9-Y1-Y1 & 3.72 & 6.50 & 0.43 & 204.27 & 21.29 & 2.78 \\
HHZ14-DT12-LI1-LI1 & 3.28 & 6.49 & 0.49 & 173.90 & 23.18 & 3.21 \\
IR 14L 116 & 3.19 & 6.11 & 0.49 & 130.13 & 25.72 & 3.04 \\
IR 97096-15-1-1-3 & 3.72 & 6.86 & 0.46 & 183.53 & 23.92 & 3.14 \\
IR 95814-10-2-2-2 & 3.56 & 6.62 & 0.46 & 148.90 & 24.70 & 3.05 \\
IR 14D 196 & 4.26 & 6.81 & 0.37 & 137.97 & 22.77 & 2.55 \\
IR 14D 198 & 3.83 & 6.33 & 0.39 & 116.53 & 22.57 & 2.50 \\
IR 14D 199 & 4.00 & 7.01 & 0.41 & 117.63 & 22.95 & 2.78 \\
Hardinath-3 (Check) & 3.89 & 6.58 & 0.41 & 197.83 & 22.63 & 2.69 \\
Grand Mean & 3.43 & 6.36 & 0.46 & 160.14 & 23.51 & 2.94 \\
F- test & $* *$ & $*$ & $* *$ & $* *$ & $* .53$ \\
SEM & 0.26 & 0.32 & 0.02 & 14.10 & 0.58 & 0.19 \\
LSD (5\%) & 0.75 & 0.92 & 0.05 & 40.37 & 1.66 & 0.54 \\
CV (\%) & 13.30 & 8.80 & 7.10 & 15.30 & 4.30 & 11.00 \\
Heritability (\%) & 67.35 & 51.85 & 85.9 & 74.46 & 86.41 & 68.64 \\
\hline & & & & & &
\end{tabular}


Coefficient of Variation (CV), Standard Error of Mean (SEM), Least Significant Difference (LSD), TGW- Thousand grain weight (grams), GY-Grain yield (t/ha), SW- Straw yield (t/ha), BMS- Biomass yield (t/ha), HI- Harvest index, FGPP-Filled grains per panicle (no's), F- test ( ${ }^{*}$-significant at $5 \%$ level of significance, ${ }^{* *}$-significant at $1 \%$ level of significance).

Heritability of the Traits: Heritability (broad sense) study of observed morphological traits revealed that plant height $(88.64 \%)$, panicle length $(81.05 \%)$, effective tillers/ $\mathrm{m}^{2}$ $(71.69 \%)$ thousand grain weight $(86.41 \%)$, harvest index $(85.9 \%)$, filled grains/panicle $(74.46 \%)$, days to flowering $(98.54 \%)$, days to maturity $(97.47 \%)$ had higher values, and flag leaf area $(65.9 \%)$, grain yield $(68.64 \%)$, straw yield $(67.35 \%)$, and biomass yield $(69.85$ $\%$ ) had comparatively lower values (Table 2 and 3). Broad sense heritability of observed traits were moderate to high in this study based on the classification of Laffite et al. (2004). Heritability values of plant height, effective tillers, panicle length, thousand grain weight, days to flowering and maturity, biomass yield and leaf area reported by Bhandari et al. (2019), Tiwari et al. (2019), and Abebe et al. (2017) were in accord to the present findings,. In contrast, high heritability for grain yield, low heritability for number of effective tillers/ $\mathrm{m}^{2}$ and plant height (Tiwari et al., 2019), slightly lower heritability for grain yield and lower heritability of harvest index (Abebe et al., 2017) were also reported. According to Griffiths et al. (2000), heritability value of a trait differs in each population and in each set of environments which suggests that the heritability values of present findings are best utilized for similar environmental condition and similar sets of genotypes for further breeding programs and traits with higher heritability in the study were indeed less influenced by the environmental conditions of the study site.

\section{CONCLUSION}

Green super rice genotype HHZ10-DT7-Y1 was found superior in performance for most of the measured morphological traits viz. highest grain yield, thousand grain weight and biomass yield, but found statistically at par with Hardinath- 3 (check) in maturity. Similarly, HHZ1-DT3-Y1-Y1 recorded highest harvest index, number of filled grains/ panicle, earliest days to flowering and maturity. Yield advantage of HHZ lines, except HHZ25-DT9-Y1-Y1, over check was 19 to almost $45 \%$, and 28.51 to $56.22 \%$ more than national average grain yield in rainfed condition. Plant height, panicle length, thousand grain weight, harvest index, days to flowering and days to maturity showed high heritability, thus the direct selection of these traits may be useful for future grain yield improvement program under rainfed lowland condition. These climate resilient green super rice genotypes are developed primarily to adapt under unconditional growing environments, and found very promising under rainfed lowlands of mid- western river basin of Nepal. Preliminary findings from this study may not be sufficient to draw final conclusions, but this study provide ample opportunities for future researches, and exploit the genetic potential of green super rice genotypes as in several Asian and African rice growing countries.

\section{ACKNOWLEDGEMENTS}

Nepal Agricultural Research and Development Fund (NARDF), National Rice Research program (NRRP), Dhanusa, Nepal and Agricultural Research Station (ARS), Dasharathpur, Surkhet respectively are highly acknowledged for funding, providing research material and

supporting the research. Authors are highly thankful to Mr. Chhiring Lama, and Mr. Suman Babu Kandel for their outstanding assistance during field experiment.

\section{REFERENCES}

1. MoALD. 2017. Statistical Information on Nepalese Agriculture. Government of Nepal, Ministry of Agriculture and Livestock Development. Monitoring, Evaluation and statistics Division (Agri statistics Section). Singha Durbar, Kathmandu, Nepal. https://nepalindata.com/resource/statistical-information-nepalese-agriculture-207374$\underline{201617 /}$ 
2. GRiSP (Global Rice Science Partnership). 2013. Rice almanac, 4th edition. Los Baños (Philippines): International Rice Research Institute. 283 p.

3. Polthanee, A., and Promkhambut, A. 2014. Impact of climate change on rice-based cropping systems and farmers' adaptation strategies in Northeast Thailand. Asian Journal of Crop Science, 6(3): 262-272. https://doi.org/10.3923/ajcs.2014.262.272.

4. Kumar, S., Dwivedi, S. K., Haris, A. A., Prakash, V., Mondal, S., Shishir, A., and Singh, K. 2015. Screening and identification of rice genotypes for drought tolerance at reproductive stage under rainfed lowland condition. Journal of Agri Search, 2(2): 105-111.

5. Ouk M, Basnayake J, Tsubo M, Fukai S, Fischer KS, Cooper, M and Nesbitt H. 2006. Use of drought response index for identification of drought tolerant genotypes in rainfed lowland rice. Field Crop Research, 99: 48-58.

6. Gumma, M. K., Gauchan, D., Nelson, A., Pandey, S., and Rala, A. 2011. Temporal changes in rice-growing area and their impact on livelihood over a decade: A case study of Nepal. Agriculture, Ecosystems and Environment, 142(3-4): 382-392. https://doi.org/10.1016/j.agee.2011.06.010.

7. Tripathi, B. P., Bhandari, H. N., and Ladha, J. K. 2018. Rice Strategy for Nepal. Acta Scientific Agriculture, 3(2): 171-180.

8. Li, Z., and Ali, J. 2017. Breeding green super rice (GSR) varieties for sustainable rice cultivation. 109-130. https://doi.org/10.19103/as.2016.0003.05.

9. IRRI. 2016. Breeding for better rice varieties/ GSR project updates in Asia and East and Southern Africa. International Rice Research Institute. http://books.irri.org/GSR-flyer.pdf

10. Saleh, A. F. M. and Bhuiyan, S. I. 1995. Crop and Rain Water Management Strategies for Increasing Productivity of Rainfed Lowland Rice Systems. Agricultural Systems, 49: 259276.

11. IRRI. 2013. Standard Evaluation System for Rice. International Rice Research Instiitute, June, 55. https://doi.org/10.1063/1.1522164.

12. Tsubo, M., Fukai, S., Basnayake, J., To, P. T., Bouman, B., and Harnpichitvitaya, D. 2007. Effects of soil clay content on water balance and productivity in rainfed lowland rice ecosystem in Northeast Thailand. Plant Production Science, 10(2): 232-241. https://doi.org/10.1626/pps.10.232.

13. Dou, F., Soriano, J., Tabien, R. E., and Chen, K. 2016. Soil Texture and Cultivar Effects on Rice (Oryza sativa, L.) Grain Yield, Yield Components and Water Productivity in Three WaterRegimes.PloSOne,11(3),e0150549.https://doi.org/10.1371/journal.pone.0150549.

14. Ahmadikhah, A., and Marufinia, A. 2016. Effect of reduced plant height on drought tolerance in rice. 3 Biotech, 6(2): 1-9. https://doi.org/10.1007/s13205-016-0542-3.

15. Fukai, S., Pantuwan, G., Jongdee, B., and Cooper, M. 1999. Screening for drought resistance in rainfed lowland rice. 64: 61-74.

16. Allah, A. A. A., Ammar, M. H., and Badawi, A. T. 2010. Screening rice genotypes for drought resistance in Egypt. Journal of Plant Breeding and Crop Science, 2(7): 205-215. http://www.academicjournals.org/jpbcs.

17. Akbar, M. R., Purwoko, B. S., Dewi, I. S., Suwarno, W. B., and Sugiyanta. 2019. Selection of doubled haploid lines of rainfed lowland rice in preliminary yield trial. Biodiversitas, 20(10): 2796-2801. https://doi.org/10.13057/biodiv/d201003.

18. Kumar, R., Sarawgi, A. K., Ramos, C., and Amarante, S. T. 2006b. Partitioning of dry matter during drought stress in rainfed lowland rice. 96: 455-465. https://doi.org/10.1016/j.fcr.2005.09.001.

19. Kumar, S., Dwivedi, S. K., Haris, A. A., Prakash, V., Mondal, S., Shishir, A., and Singh, K. 2015. Screening and identification of rice genotypes for drought tolerance at reproductive stage under rainfed lowland condition. Journal of AgriSearch, 2(2): 105-111.

20. Kumar, R., Sarawgi, A. K., Ramos, C., and Amarante, S. T. 2006a. Partitioning of dry matter during drought stress in rainfed lowland rice. 98: 1-11. https://doi.org/10.1016/j.fcr.2005.09.015. 
21. Farooq, M., Kobayashi, N., Ito, O., Wahid, A., and Serraj, R. 2010. Broader leaves result in better performance of indica rice under drought stress. Journal of Plant Physiology, 167(13): 1066- 1075. https://doi.org/10.1016/j.jplph.2010.03.003.

22. Fukai, S. 1999. Phenology in rainfed lowland rice. 64(September), 51-60.

23. Monkham, T., Jongdee, B., Pantuwan, G., Sanitchon, J., Mitchell, J. H., and Fukai, S. 2015. Genotypic variation in grain yield and flowering pattern in terminal and intermittent drought screening methods in rainfed lowland rice. Field Crops Research, 175: 26-36. https://doi.org/10.1016/j.fcr.2015.02.003.

24. Pantuwan, G., Fukai, S., Cooper, M., Rajatasereekul, S., O'Toole, J. C., and Basnayake, J. 2004. Yield response of rice (Oryza sativa L.) genotypes to drought under rainfed lowlands: 4. Vegetative stage screening in the dry season. Field Crops Research, 89(23): 281-297. https://doi.org/10.1016/j.fcr.2004.02.007.

25. Pantuwan, G., Fukai, S., Cooper, M., Rajatasereekul, S., and Toole, J. C. O. 2002. Yield response of rice (Oryza sativa L.) genotypes to drought under rainfed lowlands 2. Selection of drought resistant genotypes. 73: 169-180.

26. Bhandari, K., Poudel, A., Sharma, S., Kandel, B. P., and Upadhyay, K. 2019. Genetic Variability, Correlation and Path Analysis of Rice Genotypes in Rainfed Condition at Lamjung, Nepal. Russian Journal of Agricultural and Socio-Economic Sciences, 92(8): 274-280. https://doi.org/10.18551/rjoas.2019-08.30.

27. Abebe, T., Alamerew, S., and Tulu, L. 2017. Genetic Variability, Heritability and Genetic Advance for Yield and its Related Traits in Rainfed Lowland Rice (Oryza sativa L.) Genotypes at Fogera and Pawe, Ethiopia. Advances in Crop Science and Technology, 05(02). https://doi.org/10.4172/2329-8863.1000272.

28. Tiwari, D. N., Tripathi, S. R., Tripathi, M. P., Khatri, N., and Bastola, B. R. 2019. Genetic Variability and Correlation Coefficients of Major Traits in Early Maturing Rice under Rainfed Lowland Environments of Nepal. Advances in Agriculture, Volume 2019, Article ID 5975901, 9 pages. https://doi.org/10.1155/2019/5975901 2019.

29. Griffiths, A.J.F., Miller, J.H., Suzuki, D.T., Lewontin, R.C., Gelbart, W.M. 2000. An Introduction to Genetic Analysis. $7^{\text {th }}$ edition. New York: W. H. Freeman. Quantifying heritability. Available from: https://www.ncbi.nlm.nih.gov/books/NBK21866/ 